\title{
Oxygen saturation targeting during delivery room stabilization: what does this mean for regional cerebral oxygenation?
}

\author{
Corinna Binder-Heschl1 ${ }^{1}$, Gerhard Pichler ${ }^{1}$, Alexander Avian², Bernhard Schwaberger ${ }^{1}$, Nariae Baik-Schneditz ${ }^{1}$, \\ Lukas Mileder ${ }^{1}$, Berndt Urlesberger ${ }^{1}$ \\ ${ }^{1}$ Research Unit for Cerebral Development and Oximetry, Division of Neonatology, Medical University of Graz, Graz, Austria \\ 2 Institute for Medical Informatics, Statistics and Documentation, Medical University of Graz, Graz, Austria
}

\section{BACKGROUND:}

Recently, Oei et al. performed a meta-analysis and demonstrated that almost half of the preterm infants did not reach a 5 minute SpO2 (arterial oxygen saturation) of $80 \%$, which was associated with a higher risk of bradycardia and intraventricular haemorrhage (IVH).

A common method to measure regional cerebral oxygenation is near-infrared spectroscopy (NIRS) and can be used in preterm infants during delivery room stabilization. Our study group showed that preterm neonates developing IVH within the first days after birth had a significantly lower regional cerebral oxygenation during immediate transition.

OBJECTIVE: In the present study we investigated, whether preterm neonates with respiratory support in the delivery room and $\mathrm{SpO}_{2}$ values below the recommended target of $80 \%$ at 5 minutes after birth also show a different course of regional cerebral oxygenation, compared to infants reaching $\mathrm{SpO}_{2}$ values above $80 \%$ at 5 minutes.
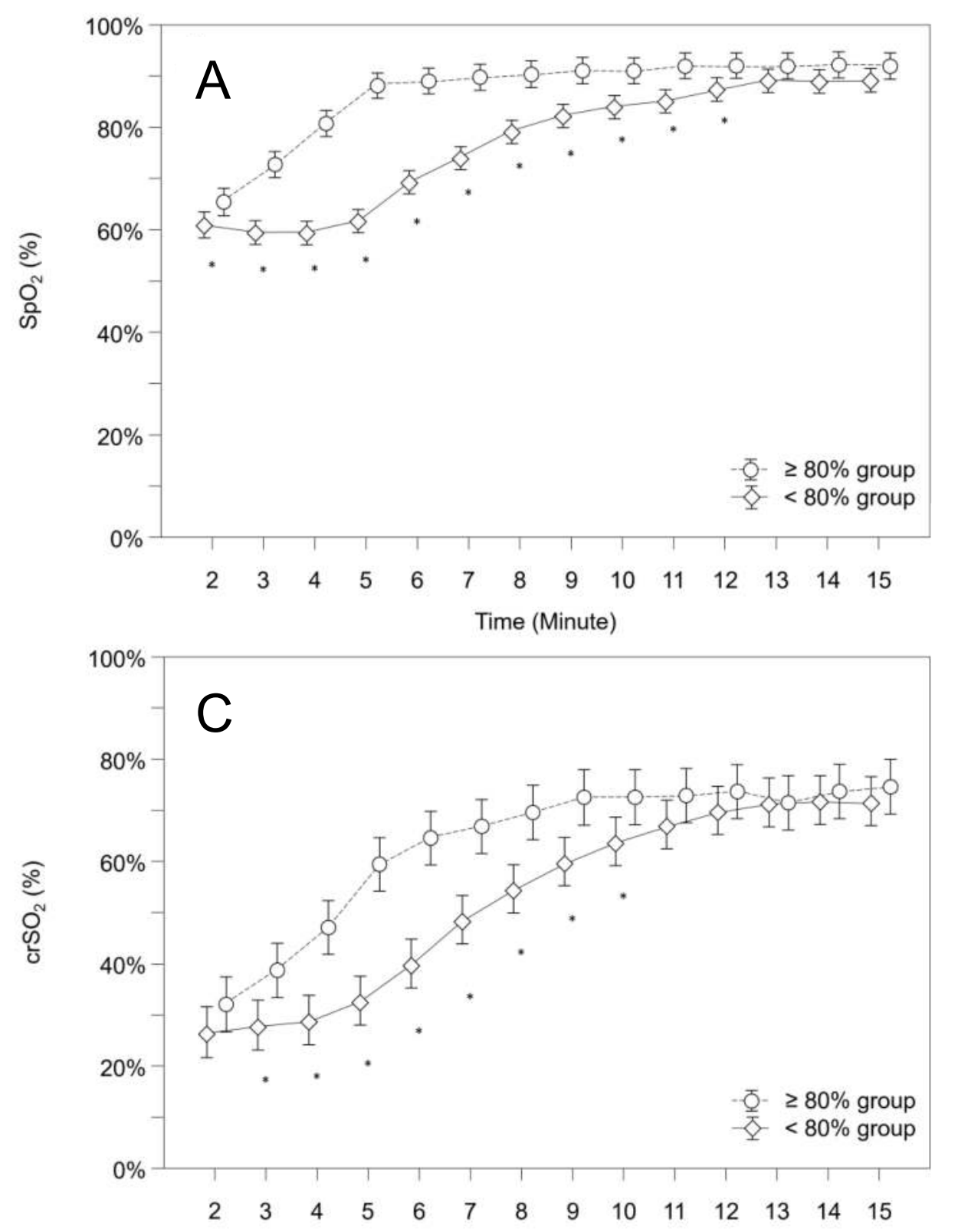
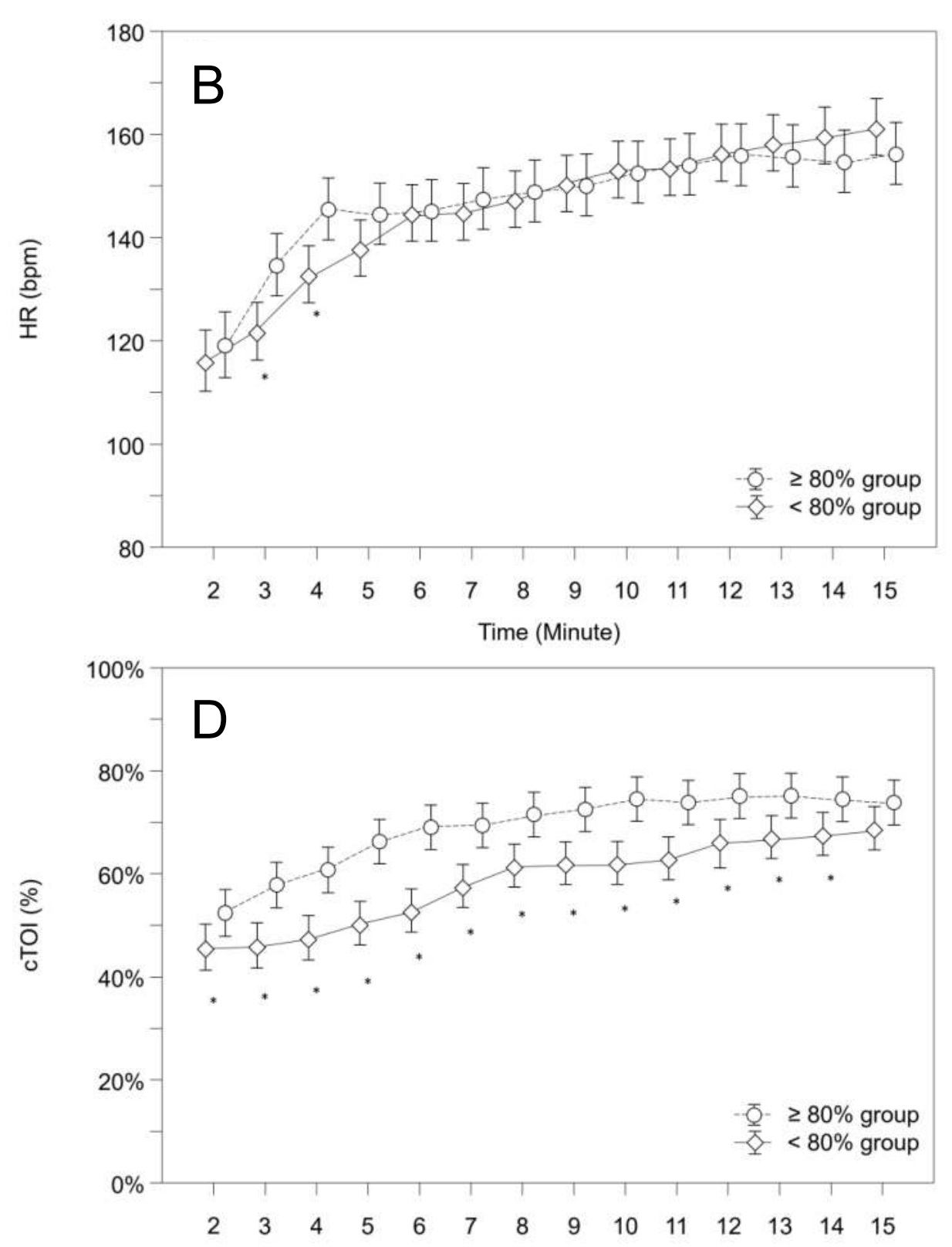

Figure 1: Courses of $(\mathbf{A})$ arterial oxygen saturation $\left(\mathrm{SpO}_{2}\right),(\mathbf{B})$ heart rate $(\mathrm{HR}),(\mathbf{C})$ INVOS cerebral regional oxygen saturation $\left(\mathrm{crSO}_{2}\right)$ and (D) NIRO cerebral tissue oxygenation index (cTOI) within both groups. Significant differences between groups $(p<0.05)$ for each minute are given with *; Data are means and 95\% Cl.

\section{METHODS:}

Retrospective analysis of 5 prospective observational studies. Regional cerebral oxygenation was measured with nearinfrared spectroscopy (NIRS) during the first 15 minutes after birth. The NIRO 200-NX and INVOS 5100C devices were used. In addition, $\mathrm{SpO}_{2}$ and heart rate $(\mathrm{HR})$ were monitored using pulse oximetry. Only preterm infants, <37 weeks of gestation, with respiratory support during delivery room stabilization were included.

According to the $\mathrm{SpO}_{2}$, infants were divided into two groups: those with a 5 minute $\mathrm{SpO}_{2} \geq 80 \%$ ( $\geq 80 \%$ group) and those with a 5 minute $\mathrm{SpO}_{2}<80 \%(<80 \%$ group). Groups were compared to each other regarding regional cerebral oxygenation $\left(\mathrm{crSO}_{2} / \mathrm{cTOI}\right), \mathrm{SpO}_{2}$ and HR.

Furthermore, we analysed whether not reaching a $\mathrm{SpO}_{2}$ of $80 \%$ at 5 minutes was associated with a regional cerebral oxygenation below the $10^{\text {th }}$ percentile at the same time point.

\section{RESULTS:}

146 preterm neonates were included. 68 infants $(47 \%)$ were allocated to the " $\geq 80 \%$ group" and 78 infants $(53 \%)$ to the " $<80 \%$ group". Preterm neonates in the " $<80 \%$ group" had a significantly lower $\mathrm{crSO}_{2}$ and cTOI ( $p$ $<0.001$ and 0.033).

There were significantly more infants of the " $<80 \%$ group" with a regional cerebral oxygenation below the $10^{\text {th }}$ percentile at 5 minutes of age.

There was a significant difference in HR between both groups $(p=0.041)$.

\begin{tabular}{|c|c|c|c|c|c|c|}
\hline & \multicolumn{3}{|c|}{$\begin{array}{c}\geqslant \geq 80 \% \text { group } " \\
n=68\end{array}$} & \multicolumn{3}{|c|}{$\begin{array}{c}"<80 \% \text { group } \\
n=78\end{array}$} \\
\hline & $\begin{array}{l}\text { NIRO } \\
n=25\end{array}$ & $\begin{array}{c}\text { INVOS } \\
n=43\end{array}$ & $\begin{array}{l}\text { Total } \\
\mathrm{n}=68\end{array}$ & $\begin{array}{l}\text { NIRO } \\
n=27\end{array}$ & $\begin{array}{c}\text { INVOS } \\
n=51\end{array}$ & $\begin{array}{l}\text { Total } \\
n=78\end{array}$ \\
\hline Gestational age, weeks & $32.0 \pm 1.8$ & $31.1 \pm 2.9$ * & $31.4 \pm 2.6$ \# & $32.7 \pm 1.6$ & $32.5 \pm 3.2$ & $32.6 \pm 2.7$ \\
\hline Birth weight, gram & $1610 \pm 574$ & $1490 \pm 540$ * & $1524 \pm 551$ \# & $1889 \pm 445$ & $1859 \pm 644$ & $1870 \pm 579$ \\
\hline APGAR $1^{\wedge}$ & $8(4-9)$ & $8(3-9)$ & $8(3-9)$ & $8(5-9)$ & $8(3-9)$ & $8(3-9)$ \\
\hline APGAR $5^{\wedge}$ & $9(8-10)^{\circ}$ & $9(6-10)^{*}$ & $9(6-10) \#$ & $8(7-9)$ & $8(6-10)$ & $8(6-10)$ \\
\hline APGAR $10^{\wedge}$ & $9(8-10)$ & $9(8-10)$ & $9(8-10)$ & $9(8-10)$ & $9(7-10)$ & $9(7-10)$ \\
\hline pH umbilical artery & $7.30 \pm 0.04$ & $7.31 \pm 0.05$ & $7.31 \pm 0.05$ & $7.31 \pm 0.05$ & $7.32 \pm 0.04$ & $7.31 \pm 0.04$ \\
\hline Male sex $\%$ & $13(52)$ & $21(49)$ & $34(50)$ & $12(44)$ & $20(39)$ & $32(41)$ \\
\hline
\end{tabular}

Table 1: Patient Demographic Characteristics.

Data are presented as mean \pm SD, unless indicated $\% \mathrm{n}(\%),{ }^{\wedge}$ median (range).

Significant difference between the groups in the NIRO subgroup $\left({ }^{\circ}\right)$, in the INVOS subgroup $\left({ }^{*}\right)$, and in total $(\#)$

CONCLUSION: Preterm infants with respiratory support during postnatal stabilization, which do not reach the $\mathrm{SpO}_{2}$ target of $80 \%$ at 5 minutes after birth, have also an impaired regional cerebral oxygenation. But even $23 \%$ of the infants in the " $\geq 80 \%$ group" had $\mathrm{CrSO}_{2}$ values below the $10^{\text {th }}$ percentile 5 minutes after birth. It remains unclear whether the threshold of $80 \% \mathrm{SpO}_{2}$ at 5 minutes is the optimal target value and whether the inclusion of NIRS into clinical practice to guide oxygen treatment may be advantageous. 